\title{
Distribution and characterization of Aegilops cylindrica species from Iran
}

3 Behnam Bakhshi ${ }^{*}$, Mohammad Jaffar Aghaei ${ }^{2}$, Eissa Zarifi', Mohammad Reza Bihamta ${ }^{3}$ and

4 Ehsan Mohseni Fard ${ }^{4}$

$6 \quad{ }^{1}$ Horticulture Crops Research Department, Sistan Agricultural and Natural Resources Research and

7 Education Center, Agricultural Research, Education and Extension Organization (AREEO), Zabol, 8 Iran

$9{ }^{2}$ Seed and Plant Improvement Institute, Agricultural Research, Education and Extension 10 Organization (AREEO), Karaj, Iran

$11{ }^{3}$ Department of Plant Breeding, The University of Tehran, Karaj, Iran

$12{ }^{4}$ Department of Agronomy and Plant Breeding, University of Zanjan, Zanjan, Iran

*Corresponding author’s email: behnam.bakhshi@gmail.com , b.bakhshi@areeo.ac.ir

\section{Abstract}

Jointed goatgrass (Aegilops cylindrica Host; $2 \mathrm{n}=4 \mathrm{x}=28, \mathrm{C}^{\mathrm{c}} \mathrm{C}^{\mathrm{c}} \mathrm{D}^{\mathrm{c}} \mathrm{D}^{\mathrm{c}}$ ) is a tetraploid remote relative of bread wheat (Triticum aestivum $\mathrm{L} ; 2 \mathrm{n}=6 \mathrm{x}=42$, AABBDD) with 2 genomes and 28 chromosomes. The diversity center of this species is in the Fertile Crescent and in central Asia and could also be found in many places in Iran. In this experiment, 359 accessions provided by National Plant Gene

21 Bank of Iran (NPGBI) were used. Based on the geographical distribution, the highest distribution of 22 Ae. cylindrica are from North, West and North West regions of Iran. The distribution data of Ae. 23 cylindrica showed that the distribution centers in Iran are more than those reported in previous 24 studies in Iran. Chromosome counting showed that all Ae. cylindrica accessions are tetraploid $25(2 n=4 x=28)$. Results of factor analysis for 9 morphological chromosome traits showed that 26 karyotypic variation within accessions are related to the length of chromosomes and there is 27 difference between accessions for their total chromosome length, but the karyotype of different 
accessions were almost the same for the symmetry. Low coefficient of variation in morphological

2 traits as well as symmetric karyotypes of Ae. cylindrica species observed in this study could lead us

3 to more confidently say that Ae. cylindrica could be a recently evolved species among remote

4 relatives of bread wheat.

5 Key words: Remote relatives, Wheat, Cytogenetics, Chromosome, Genetic diversity.

\section{Introduction}

8 Jointed goatgrass, originated from two species, is native to the Mediterranean, Middle East, Asia, 9 and was also introduced to the Great Plains and the Pacific northwest of the United States $(1,2)$. It 10 is a winter annual grass weed that infests over 3 million ha of winter wheat in the Pacific 11 Northwest and Great Plains regions of the USA (3). It reduces winter wheat yields by interference 12 and lowers harvested grain quality. Average yield loss with moderate to dense Ae. cylindrica 13 infestations has been estimated to be $25 \%(4,5)$ and it also has been estimated that the economic 14 cost of Ae. cylindrica to winter wheat producers in the western United States is $\$ 145$ million 15 annually (6). Jointed goatgrass and winter wheat are closely related. Therefore, the development 16 of selective herbicides to control this weed in winter wheat has been problematic.

17 Aegilops cylindrica is a bush type plant with 20-40 centimeters. It is characterized by narrow leaves 18 (4-5 centimeters), none or very little hair, a narrow lanceolate spike (8 to 19 centimeters), almost 19 ended with two incomplete spikelet. Each spike consists of 6-11 spikelets and breaks off entirely or 20 disintegrates into segments. Each spikelet holds one to three seeds that are reddish-brown in color 21 and reach maturity in mid-summer which is when the spikelets are fragile $(1,2,4,7)$ (Figure 1). 

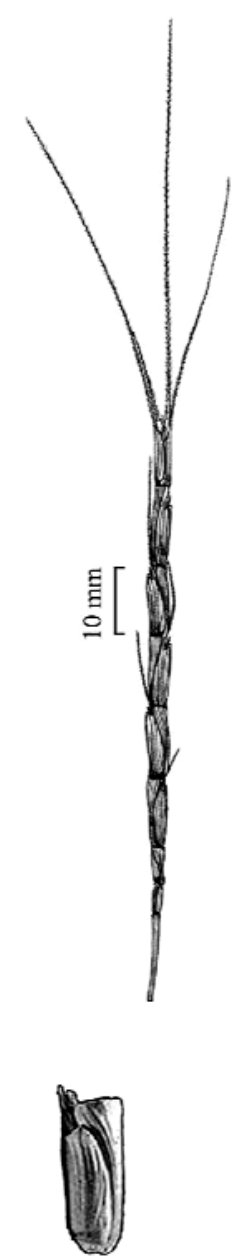

Figure 1. Spike and spikelet of Ae. cylindrica species.

4 The genomic constitution of Ae. cylindrica was determined by the analyses of chromosome pairing, 5 storage proteins, isozymes, and differences in restriction length patterns of repeated nucleotide 6 sequences (8). These studies identified the diploid species Ae. caudata $\mathrm{L}$. $(2 \mathrm{n}=2 \mathrm{x}=14, \mathrm{CC})$ and Ae. 7 tauschii Coss. $(2 \mathrm{n}=2 \mathrm{x}=14, \mathrm{DD})$ as the donor of the $\mathrm{C}$ and the $\mathrm{D}$ genome of Ae. cylindrica, respectively 8 (8). Previously, the cytoplasm of Ae. cylindrica was shown to be contributed by Ae. tauschii $(9,10)$ 9 but, more recent analysis with chloroplast microsatellite markers has shown that both Ae. tauschii (D10 type cytoplasm) and Ae. markgrafii (C-type cytoplasm) have contributed their cytoplasms to Ae. 11 cylindrica (11). High genome homology shared between Ae. cylindrica and it's progenitor species and 12 low intra-species polymorphism in Ae. cylindrica indicated it as a new species with little chromosome 13 changes. The $\mathrm{D}$ genome chromosomes of Ae. cylindrica species are more similar to Ae. tauschii 14 biotypes and $\mathrm{D}^{\mathrm{cr} 2}$ genome of hexaploid cytotype of Ae. crassa species than D genome of bread wheat 
$1(12,13)$. These results indicate that there are different versions of $\mathrm{D}$ genomes for both Ae. cylindrica 2 and $T$. aestivum species.

3 This species has wide distribution from Western Europe to East Asia and even North America. The 4 diversity center of this species is in the Fertile Crescent and in central Asia and could also be found 5 in many places in Iran (1). Ae. cylindrica has spread westward to Greece, Bulgaria, Romania, 6 Kosovo, Montenegro, Serbia, and Hungary. To the east, Ae. cylindrica is found in central Asia. 7 Northwards, it is present in the Caucasus region and along the Black Sea coast. Though rare, this 8 species is also present in the western arc of the Fertile Crescent involving Lebanon, Jordan, Syria, 9 northern Iraq, and northwestern Iran. Ae. cylindrica is also adventives in many parts of Europe, 10 Asia, and America (1).

11 The geographic distribution of Ae. cylindrica encompasses and extends beyond areas, where its 12 diploid progenitors, Ae. tauschii and Ae. markgrafii, can be found (Figure 2).
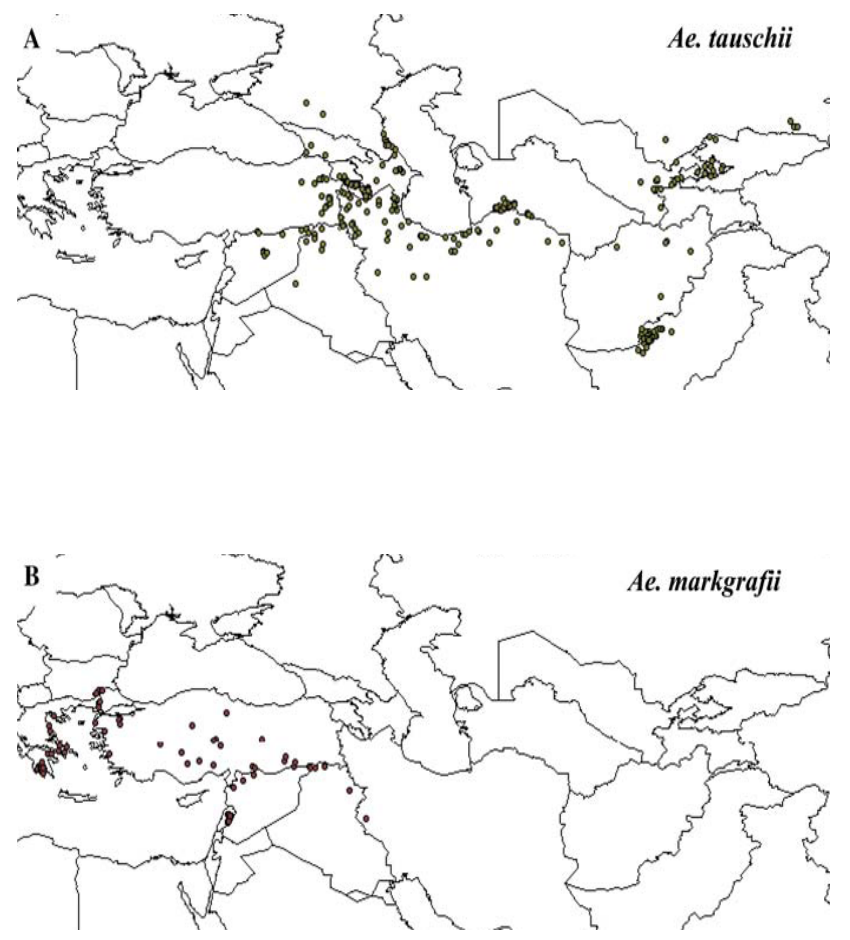


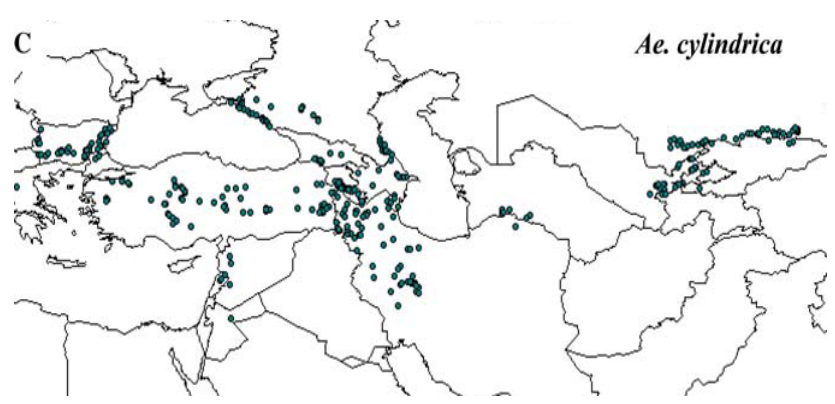

Figure 2. Maps showing the distribution of collections of Ae. tauschii (a), Ae. markgrafii (b), and Ae. cylindrica (c). The geographic coordinates were obtained from the system-wide information network for genetic resources (SINGER; http://singer.cgiar.org/).

Throughout its range of distribution, Ae. cylindrica is considered a weedy species, particularly in common wheat fields, where it chronically infests fields in the Mediterranean, the Middle East, Europe, and the United States of America (USA) (1, 3, 14). Jointed goatgrass has also been suggested as a source of genetic variation for wheat improvement (15-17) because it is a close relative of common wheat—both species carry the D genome donated by Ae. tauschii $(18,19)$. In addition, natural hybridization between wheat and jointed goatgrass suggests a potential for gene flow between these species under field conditions $(20,21)$. Thus, there is considerable interest in understanding various aspects of the evolution of Ae. cylindrica for its better management and use. Cytogenetic and molecular-based analyses suggested that the D genomes of Ae. cylindrica and $T$. aestivum were contributed by different biotypes of Ae. tauschii $(12,13)$. The D genome of hexaploid wheat has been shown to be more closely related to the $\mathrm{D}$ genome of Ae. tauschii ssp. strangulata than to Ae. tauschii ssp. Tauschii (22-24), whereas the D-type plastome and the D genome of Ae. cylindrica are more closely related to Ae. tauschii ssp. tauschii than to Ae. tauschii ssp. strangulate (11).

Although molecular genetic diversity and ploidy level of Ae. tauschii has been reported before $(25,26)$, no extensive study has been done to identify cytogenetic and morphologic characteristics of this species. We have collected many accessions from different regions of Iran that it could be remarkable to identify potential genetic diversity among these accessions. In this study, we analyzed chromosomes features of Ae. cylindrica as well as distribution and morphological 
1 characteristics of this species because of wide distribution of this species in Iran. Since this

2 species is a relative of bread wheat it is important to identify available genetic diversity in this

3 species to be used in necessary condition in bread wheat breeding programs.

\section{$5 \quad$ 2.Materials and Methods}

6 2.1.Plant material: 359 accessions were used in this experiment, which were provided from 7 National Plant Gene Bank of Iran (NPGBI). These accessions were collected from sixteen 8 provinces of Iran (West Azarbaijan, East Azarbaijan, Ardebil, Zanjan, Qazvin, Kurdistan, 9 Hamedan, Kermanshah, Ilam, Lorestan, Chaharmohal Bakhtiari, Mazandaran, Tehran, Esfahan, 10 Semnan and Khorasan). Traits and measuring methods are shown in the Table 1. Evaluation of 11 all traits was conducted using three replications of each accession. The mean and mode was 12 calculated for quantitative and qualitative traits, respectively. Estimated statistical parameters 13 traits were calculated for quantitative traits. Shannon and Weaver diversity index were 14 calculated for measuring qualitative traits. Non-standard values of diversity index (Hc) and 15 standard diversity index (SDI) was calculated as follows(27):

$$
H c=-\sum_{i=1}^{n} p i \log _{e} p i \quad S D I_{e}=H c / \log _{e} n
$$

17 In this formula, for certain traits, such as $\mathrm{c}, \mathrm{n}$, including the number of phenotypic classes and $\mathrm{Pi}$ is equal to the frequency of bushes.

20 2.2. Chromosome counting: Based on the technique, developed at International Maize and Wheat 21 Improvement Center (CIMMYT) institute (28), root tips were collected between 9 AM to 10:30 AM, 22 and then placed in a Petri dish, on a filter paper moistened with $\alpha$-bromonaphthalene pre-treatment 23 solution. The samples were pre-treated about 2.5 to 3.5 hours, but generally 3 hours as pre-treatment 24 time which was used in this study, resulting satisfying chromosome contraction and high mitotic 25 index. After pre-treatment, the root tips were transferred to vials, containing $0.2 \%$ aceto-orcein and 
1 refrigerated $\left(4^{\circ} \mathrm{C}\right)$, until they are being used. Afterwards, the root tips were transferred to $2 \%$ aceto-

2 orcein, in order to intensify the staining for 2 days before squashing. After staining the aceto-orcein

3 was removed from the vial and $45 \%$ acetic acid was added to fill about a quarter of the vial. Vial was

4 heated over a flame to bring the contents to a slow boiling. After boiling, the vial contents ( $45 \%$ acetic

5 acid + root tip) were transferred into an evaporating dish. A root tip was taken from it and placed over

6 on filter paper to remove extra acetic acid. Apical root tip measuring 2-2.5mm was cut and placed on

7 dry microscope slide. The root tip was squashed by an arrow-head needle, and a small drop of $45 \%$

8 acetic acid was quickly added to the squashed tissue. The slide was then slightly warmed and a cover

9 glass was placed gently over on the macerated cellular area. The cover glass slides were gently dabbed

10 with coarse filter paper, the slide was heated slightly, placed between folded filter paper on a flat

11 surface and thumb pressure applied directly to the cover glass. After squashing, the slide was suitable

12 for observing chromosomes by microscope.

13 2.3. Karyotype preparation: In order to prepare karyotypes of Ae. cylindrica, 12 accessions of Ae.

14 cylindrica were used (Table 2).

2.4. Study of Karyotypes: Chromosomes are named according to the location of centromere in the chromosome (26). Comparison between karyotypes in different accessions of a species was performed by comparing their symmetry in this study. In addition, the Stebbins method for determining the degree of symmetry has been used. Stebbins (1971) believes this as suitable method to recognize the role of karyotypes in evolution of the species. In addition, total form percentage index (TF) (29), the relative percentage of the longest chromosome to the shortest chromosomes (S) (30), coefficient chromosomal length variations (CV) (31), the average ratio of long to short arm (R) (30) and range of chromosome length variation (V) (32) were calculated in this study. Furthermore, evaluation of

23 karyotype evolution was calculated using Dispersion Index (DI) to show a few differences that were

24 not visible in Stebbins indicators (33). Factor analysis for morphological features of chromosomes based on principal component analysis and Varimax rotation was also conducted in this study. For measuring different parts of the chromosomes and for analyzing morphological data of chromosomes,

Micromeasure software (34) and the SPSS software were used, respectively.

Table 1. Traits and methods of measure.

\begin{tabular}{lll}
\hline Rows & Traits & Measuring methods \\
\hline 1. & Plant height & Measuring stem length per plant in cm \\
2. & Maturity date & Counting the number of days from 21 March to 50\% of plant maturity
\end{tabular}




\begin{tabular}{|c|c|c|}
\hline 3. & Flowering date & Counting the number of days from 21 March to $50 \%$ of plant Flowering \\
\hline 4. & Spikelet seed number & Counting the number of seed per spikelets (per plant) \\
\hline 5. & Leaf number of rachis & Counting the number of stem leaves (per plant) \\
\hline 6. & $\begin{array}{l}\text { Spikelet number per } \\
\text { spike }\end{array}$ & Counting the number of spikelets (per spike) \\
\hline 7. & Node number of rachis & Counting the number of stem nodes (per plant) \\
\hline 8. & Kernel length & Length measurement of seeds (per plant) (mm) \\
\hline 9. & Spike length & Measuring spike length (per plant) $(\mathrm{cm})$ \\
\hline 10. & Spikelet length & Spikelet length measurement (per plant) (mm) \\
\hline 11. & Length of spikelet glume & Measuring length of spikelet glume (per plant) (mm) \\
\hline 12. & Kernel width & Measuring kernel width (per plant) (mm) \\
\hline 13. & Spikelet width & Measuring spikelet width (per plant) (mm) \\
\hline 14. & Width of spikelet glume & Measuring spikelet glume width (per plant) (mm) \\
\hline 15. & Rachis width & Measuring rachis width (per plant) (mm) \\
\hline 16. & Spike width & Measuring spike width (per plant) (mm) \\
\hline 17. & Seed tissue & $\begin{array}{l}\text { Named grain flour, half glass and glass, with the numbers } 3,5 \text { and } 7 \text {, } \\
\text { respectively }\end{array}$ \\
\hline 18. & Stamen color & Named white, yellow and brown stamens, with numbers 1,2 and 3 , respectively \\
\hline 19. & Seed color & Named white, red and purple grains, with numbers 1, 2 and 3, respectively \\
\hline 20. & Glume color & $\begin{array}{l}\text { Named white, red to brown and purple to black with numbers } 1,2 \text { and } 3 \text {, } \\
\text { respectively }\end{array}$ \\
\hline 21. & Spike-axis fragility & $\begin{array}{l}\text { Named very fragile, moderate and strong spike with numbers } 1,2 \text { and } 3 \text {, } \\
\text { respectively }\end{array}$ \\
\hline 22. & Growth habit & $\begin{array}{l}\text { Named standing, half standing and asleep plants with numbers } 1,3 \text { and } 5 \text {, } \\
\text { respectively }\end{array}$ \\
\hline 23. & Glume hairs & $\begin{array}{l}\text { Named glabrous, with less cracking, medium and high Glume hairs with } \\
\text { numbers } 1,3,5 \text { and } 7 \text {, respectively }\end{array}$ \\
\hline
\end{tabular}

Table 2. Accessions of Ae. cylindrica used in karyotype study.

\begin{tabular}{|c|c|c|c|c|c|c|}
\hline \multirow{2}{*}{ Province } & \multirow{2}{*}{ City } & \multirow{2}{*}{ Accession No. } & \multicolumn{2}{|c|}{ Longitude } & \multicolumn{2}{|c|}{ Latitude } \\
\hline & & & Degree & Seconds & Degree & Seconds \\
\hline West Azarbaijan & Naghadeh & 50 & 45 & 22 & 36 & 57 \\
\hline Lorestan & Borujerd & 96 & 57 & 20 & 37 & 28 \\
\hline Zanjan & Zanjan & 363 & 48 & 29 & 36 & 40 \\
\hline Kermanshah & Songhor & 286 & 47 & 34 & 36 & 47 \\
\hline East Azerbaijan & Maragheh & 406 & 46 & 16 & 37 & 24 \\
\hline East Azerbaijan & Hashtrud & 408 & 47 & 4 & 37 & 28 \\
\hline Ilam & Shirvan & 312 & 46 & 34 & 33 & 46 \\
\hline Ardabil & Ardabil & 332 & 48 & 17 & 38 & 15 \\
\hline Kermanshah & West Islamabad & 379 & 46 & 32 & 34 & 7 \\
\hline East Azerbaijan & Urmia & 45 & 45 & 2 & 37 & 32 \\
\hline Kermanshah & Javanrud & 381 & 46 & 22 & 35 & 3 \\
\hline Hamadan & Hamadan & 393 & 48 & 31 & 34 & 48 \\
\hline
\end{tabular}

2

\section{3. Results and Discussion}

4 3.1. Geographical distribution of of Ae. cylindrica accessions in Iran: Investigation on collecting 5 location and geographical distribution of Ae. cylindrica accessions reveales that this species 6 predominantly grows in the range of 800 to 2000 meters altitude. Thus this species is adapted to 7 mountainous ecosystems and not to low altitude ecosystems of Caspian shores, southern shore, 
1 Khuzestan and Ilam. Also, the results of the geographical distribution using ILWIS software also 2 showed that the highest distribution of Ae. cylindrica was from that North, West and North West 3 regions, including East Azarbaijan, West Azarbaijan and Kermanshah provinces contrasting to the 4 southern and south-east regions that showed the lowest distribution (Figure 3). However, it may be 5 found anywhere on the mountainous areas of Alborz and Zagros. Some populations could even be 6 found on briny margins of Uromieh lake and Semnan, Northern Khorasan and around Qom. 7 Whereas, Ae. cylindrica doesn't grow on salty deserts of central and southern Iran. While, it is 8 abundant in central Iranian land, Ae. cylindrica is usually found in the more elevated northern strip 9 of the central Iranian desserts and not in the more arid region of southern and central areas.

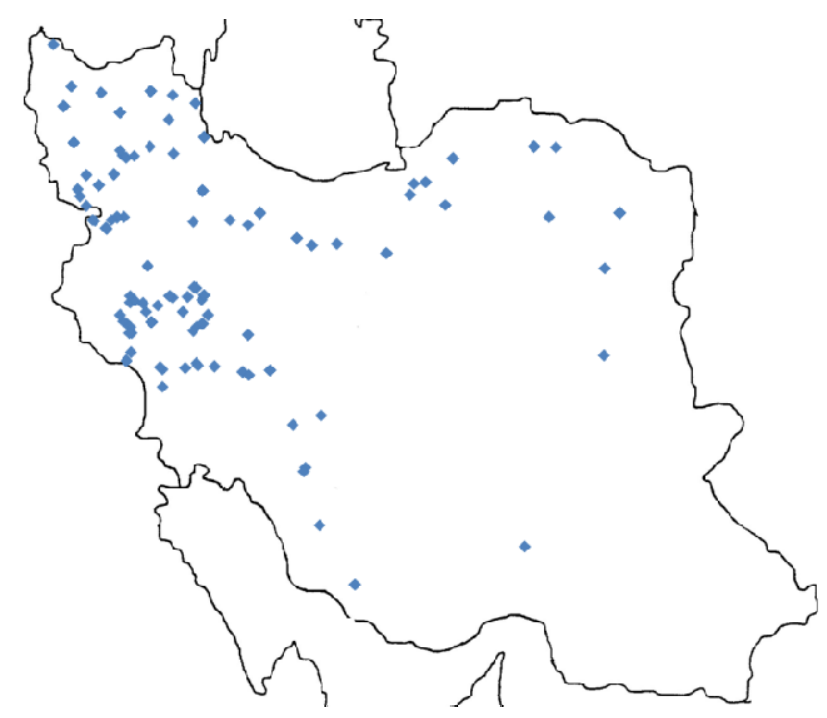

Figure 3. Geographical distribution of Ae. cylindrica in Iran.

The present investigation on the geographical distribution of Ae. cylindrica showed that the distribution centers are more than reported in a previous study (11) in Iran. In the present study, in addition to north, west and northwest, northeast and southwest of Iran have also been identified as distribution centers for this species. The results also showed that this species mostly present in mountain ecosystems and it is not found at low altitude ecosystems such as the margins and the southern coast ecosystems of Caspian Sea. Previous studies indicated that the evolution of bread wheat occurred in high altitudes of Caspian Sea ecosystems $(35,36)$. On the other hand the results of this study showed that the Ae. cylindrica species has a wide distribution in this region. With this explanation, the possibility of challenging unproven hypothesis that Ae. cylindrica had a potential to be as a donor of hexaploid wheat D genome (37) might be more acceptable. 
3.2. Statistical parameters in the studied traits of Ae. cylindrica species: Rachis width, spikelet seed number, plant height, kernel width and leaf number of rachis traits showed the highest phenotypic coefficient of variation, with $13.14,11.33,10.85,10.43$ and 10.11 percent, respectively. Most of these traits have been also observed among traits with high diversity in other collected accession in Iran including Aegilops tauschi and Aegilops crassa $(38,39)$. Furthermore, maturity date, spikelet length and length of spikelet glume traits indicated the lowest phenotypic coefficient of variation with 4.80, 5.02, and 5.61 percent. Most standard deviations were also related to plant height, flowering date and maturity date and the lowest standard deviation were related to rachis width, spikelet width and width of spikelet glume (Table 3). White and flour form kernel, brown and glabrous glumes, moderate fragility spikes, brown stamens and standing bushes were predominantly observed traits in the research field. Furthermore, growth habit showed the most variation using non-standard and standard diversity index of Shannon-Weaver (40). Thus, according to Shannon-Weaver index, growth habit could be introduced as the most effective qualitative trait to distinguish Ae. cylindrica populations (Table 4). Relatively low level of phenotypic variation coefficients for different traits were obtained in this study showing that this species is relatively new. However, it has been observed high genetic diversity for Aegilops tauschi in northern area of Iran (38).

Table 3. Statistical parameters for quantitative traits evaluated in the collection of Ae. cylindrical.

\begin{tabular}{|c|c|c|c|c|c|c|c|c|c|}
\hline & Mean & Mod & Middle & Minimum & Maximum & $\begin{array}{l}\text { Range of } \\
\text { Variation }\end{array}$ & $\begin{array}{l}\text { Standard } \\
\text { deviation }\end{array}$ & Variance & $\begin{array}{l}\text { Coefficient } \\
\text { of variation }\end{array}$ \\
\hline Plant height & 59.67 & 59.00 & 60.33 & 38.33 & 89.67 & 51.33 & 6.47 & 41.88 & 10.85 \\
\hline Flowering date & 65.12 & 67.00 & 66.00 & 58.00 & 93.00 & 35.00 & 4.34 & 18.82 & 6.66 \\
\hline Maturity date & 89.23 & 87.00 & 88.00 & 58.00 & 98.00 & 40.00 & 4.28 & 18.32 & 4.80 \\
\hline $\begin{array}{l}\text { Leaf number of } \\
\text { rachis }\end{array}$ & 3.46 & 3.33 & 3.33 & 2.67 & 4.33 & 1.67 & 0.35 & 0.12 & 10.11 \\
\hline $\begin{array}{l}\text { Spikelet } \\
\text { number }\end{array}$ & 2.04 & 2.00 & 2.00 & 1.33 & 3.00 & 1.67 & 0.23 & 0.05 & 11.33 \\
\hline $\begin{array}{l}\text { Spikelet number per } \\
\text { spike }\end{array}$ & 9.28 & 9.00 & 9.33 & 6.67 & 11.67 & 5.00 & 0.85 & 0.73 & 9.18 \\
\hline $\begin{array}{l}\text { Node number of } \\
\text { rachis }\end{array}$ & 2.92 & 3.00 & 3.00 & 2.00 & 3.67 & 1.67 & 0.21 & 0.04 & 7.14 \\
\hline Kernel width & 7.08 & 6.83 & 7.07 & 5.47 & 9.10 & 3.63 & 0.52 & 0.27 & 7.39 \\
\hline Spike length & 8.65 & 9.00 & 8.67 & 6.00 & 10.33 & 4.33 & 0.74 & 0.54 & 8.53 \\
\hline Spikelet length & 11.72 & 11.73 & 11.73 & 8.20 & 14.47 & 6.27 & 0.59 & 0.35 & 5.02 \\
\hline $\begin{array}{l}\text { Length of spikelet } \\
\text { glume }\end{array}$ & 9.28 & 10.17 & 9.83 & 8.23 & 11.23 & 3.00 & 0.55 & 0.30 & 5.61 \\
\hline Kernel width & 2.33 & 2.40 & 2.33 & 1.63 & 5.63 & 4.00 & 0.24 & 0.06 & 10.43 \\
\hline Spikelet width & 2.69 & 2.67 & 2.67 & 2.27 & 3.63 & 1.37 & 0.17 & 0.03 & 6.51 \\
\hline $\begin{array}{l}\text { Width of spikelet } \\
\text { glume }\end{array}$ & 2.88 & 2.87 & 2.87 & 2.40 & 4.27 & 1.87 & 0.19 & 0.04 & 6.70 \\
\hline
\end{tabular}


$\begin{array}{llllllllll}\text { Rachis width } & 1.27 & 1.17 & 1.27 & 0.83 & 1.90 & 1.07 & 0.17 & 0.03 & 13.14\end{array}$

$\begin{array}{llllllllll}\text { Spike width } & 2.82 & 2.83 & 2.80 & 2.30 & 4.30 & 2.00 & 0.22 & 0.05 & 7.67\end{array}$

Table 4. Statistical parameters for qualitative traits evaluated in the collection of Ae. cylindrical.

\begin{tabular}{|c|c|c|c|c|c|c|}
\hline & Mod & $\begin{array}{l}\text { Range } \\
\text { variation }\end{array}$ & of Minimum & Maximum & $\begin{array}{l}\text { Standard diversity } \\
\text { index }\end{array}$ & $\begin{array}{l}\text { Non-standard } \\
\text { diversity index }\end{array}$ \\
\hline Kernel tissue & 3 & 0 & 3 & 3 & 0 & 0 \\
\hline Stamen color & 3 & 2 & 1 & 3 & 0.10 & 0.17 \\
\hline Kernel color & 3 & 0 & 3 & 3 & 0 & 0 \\
\hline Glume color & 2 & 0 & 2 & 2 & 0 & 0 \\
\hline Spike-axis fragility & 3 & 2 & 3 & 5 & 0.04 & 0.07 \\
\hline Grows habit & 1 & 4 & 1 & 5 & 0.58 & 0.92 \\
\hline Glume hairs & 1 & 6 & 1 & 7 & 0.06 & 0.11 \\
\hline
\end{tabular}

2

3

3.3. Karyotype analysis of accessions: Chromosome counting showed that most of Ae. cylindrica accessions are tetraploid $(2 \mathrm{n}=4 \mathrm{x}=28)$. Furthermore, cytogenetic studies showed no aneuploids and $\mathrm{B}$ chromosomes, but difference in chromosome length is shown in this study. Collecting place and accession No are presented in Table 2 and chromosomes count, satellites count in karyotype and also karyotypic formula are shown in Table 5. The metaphase cell and ideogram of various accessions are presented in figures 4 to 15 . All investigated accessions had a satellite in the short arm of chromosomes No. 8. The presence of satellite in the same pair of chromosomes is also reported (41). Considerable variation was observed in total length of chromosomes (TLC) and the average length of chromosomes (C). High variation in length of chromosomes may be a sign of genome adaptation of this species to those places from where they have been collected. The largest chromosome (11.33 micrometer) was found in Zanjan and the smallest chromosome (4.87 micrometer) was observed in the accession of Urmia and both of them were sub-metacentric. Maximum and minimum of long arm to short arm ratio was observed in Islam Abad Gharb (2.129) and in Shirvan (1.78) accessions, respectively. For total form percentage index (TF), the maximum (35.32) and minimum (31.18) TF was observed in Ardabil and Zanjan accessions, respectively. This data shows that karyotypes of Ardebil and Zanjan accessions have the highest and the lowest symmetry. The highest coefficient of variation (CV) was found in accession from Naghadeh and the lowest coefficient of variation was found in the Javanrud accession. All of the accessions that were collected from the north-west and the West of Iran, belonged to A2 position of the Stebbins Table, indicating a relatively symmetrical karyotype for recently evolved species with short evolutionary history. Also, distribution index of chromosome (DI) showed that the Hashtrud accession had the highest DI (7.43) and Zanjan accession had the lowest DI (18.5). This observation indicated that 
1 the Hashtrud accession had the highest symmetry in contrast to Zanjan accession. DI could be more

2 reliable than other indicators because three important karyotypic criteria, including; variation in

3 chromosomes length, centromere position and relative size of chromosomes are involved in DI

4 calculation (Table 6).

Table 5. Collecting place, chromosomes count, satellites count and karyotypic formula of Ae. cylindrical.

\begin{tabular}{llll}
\hline Collecting place & Chromosomes count & Satellites count & Karyotypic formula \\
\hline Naghadeh & 28 & 1 & $2 \mathrm{~m}^{*}+6 \mathrm{sm}^{*}+6 \mathrm{st}^{*}$ \\
Borujerd & 28 & 1 & $1 \mathrm{~m}+8 \mathrm{sm}+5 \mathrm{st}$ \\
Zanjan & 28 & 1 & $2 \mathrm{~m}+6 \mathrm{sm}+6 \mathrm{st}$ \\
Songhor & 28 & 1 & $4 \mathrm{~m}+4 \mathrm{sm}+6 \mathrm{st}$ \\
Maragheh & 18 & 1 & $2 \mathrm{~m}+9 \mathrm{sm}+3 \mathrm{st}$ \\
Hashtrud & 28 & 1 & $1 \mathrm{~m}+9 \mathrm{sm}+4 \mathrm{st}$ \\
Shirvan & 28 & 1 & $5 \mathrm{~m}+8 \mathrm{sm}+1 \mathrm{st}$ \\
Ardabil & 28 & 1 & $3 \mathrm{~m}+9 \mathrm{sm}+2 \mathrm{st}$ \\
West Islamabad & 28 & 1 & $3 \mathrm{~m}+6 \mathrm{sm}+5 \mathrm{st}$ \\
Urmia & 28 & 1 & $1 \mathrm{~m}+12 \mathrm{sm}+1 \mathrm{st}$ \\
Javanrud & 28 & 1 & $2 \mathrm{~m}+10 \mathrm{sm}+3 \mathrm{st}$ \\
Hamadan & 28 & 1 & $\mathrm{~m} \mathrm{sm}+5 \mathrm{st}$ \\
\hline
\end{tabular}

* m; Metacentric chromosome, sm; Submetacentric chromosome and st; Subtelocentric chromosome

Table 6. Karyological characteristics of Ae. cylindrica accessions.

\begin{tabular}{|c|c|c|c|c|c|c|c|c|c|c|}
\hline Collecting place & 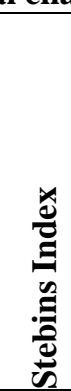 & 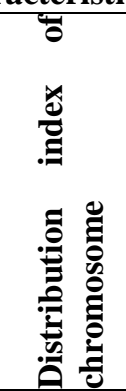 & 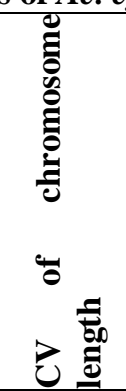 & 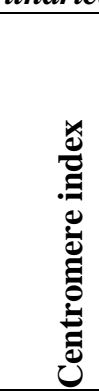 & 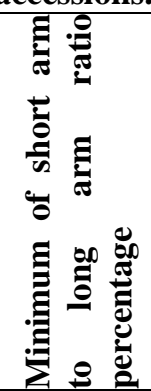 & 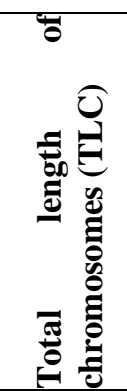 & 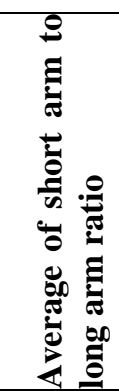 & 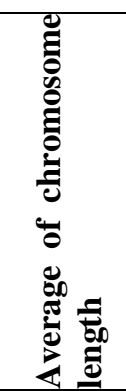 & 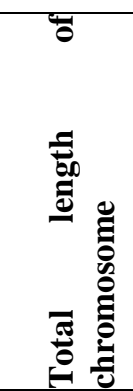 & 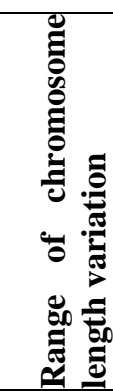 \\
\hline Naghadeh & $2 \mathrm{~A}$ & 6.46 & 13.48 & 0.32 & 65.01 & 32.36 & 2.09 & 8.68 & 121.61 & 3.77 \\
\hline Borujerd & $2 \mathrm{~A}$ & 5.84 & 12.09 & 0.32 & 66.51 & 32.54 & 2.07 & 7.57 & 105.97 & 3.12 \\
\hline Zanjan & $2 \mathrm{~A}$ & 5.19 & 11.45 & 0.31 & 68.42 & 31.19 & 2.20 & 9.22 & 129.16 & 3.57 \\
\hline Songhor & $2 \mathrm{~A}$ & 5.65 & 11.90 & 0.32 & 67.77 & 32.21 & 2.10 & 7.46 & 104.46 & 2.95 \\
\hline Maragheh & $2 \mathrm{~A}$ & 6.41 & 12.84 & 0.33 & 67.13 & 33.31 & 2.00 & 8.43 & 118.12 & 3.41 \\
\hline Hashtrud & $2 \mathrm{~A}$ & 7.44 & 15.06 & 0.33 & 60.76 & 33.07 & 2.02 & 7.70 & 107.88 & 3.87 \\
\hline Shirvan & $2 \mathrm{~A}$ & 7.25 & 12.88 & 0.23 & 65.38 & 32.19 & 1.78 & 9.13 & 127.89 & 3.89 \\
\hline Ardabil & $2 \mathrm{~A}$ & 6.12 & 11.19 & 0.35 & 69.74 & 35.33 & 1.83 & 6.76 & 94.64 & 2.49 \\
\hline West Islamabad & $2 \mathrm{~A}$ & 6.10 & 12.99 & 0.31 & 64.19 & 31.96 & 2.13 & 8.27 & 115.87 & 3.71 \\
\hline Urmia & $2 \mathrm{~A}$ & 5.93 & 11.15 & 0.34 & 69.07 & 34.73 & 1.88 & 5.85 & 81.94 & 2.18 \\
\hline Javanrud & $2 \mathrm{~A}$ & 5.62 & 11.04 & 0.33 & 69.75 & 33.75 & 1.96 & 6.76 & 94.68 & 2.43 \\
\hline Hamadan & $2 \mathrm{~A}$ & 6.61 & 12.98 & 0.33 & 65.82 & 33.71 & 1.97 & 6.45 & 90.38 & 2.77 \\
\hline
\end{tabular}



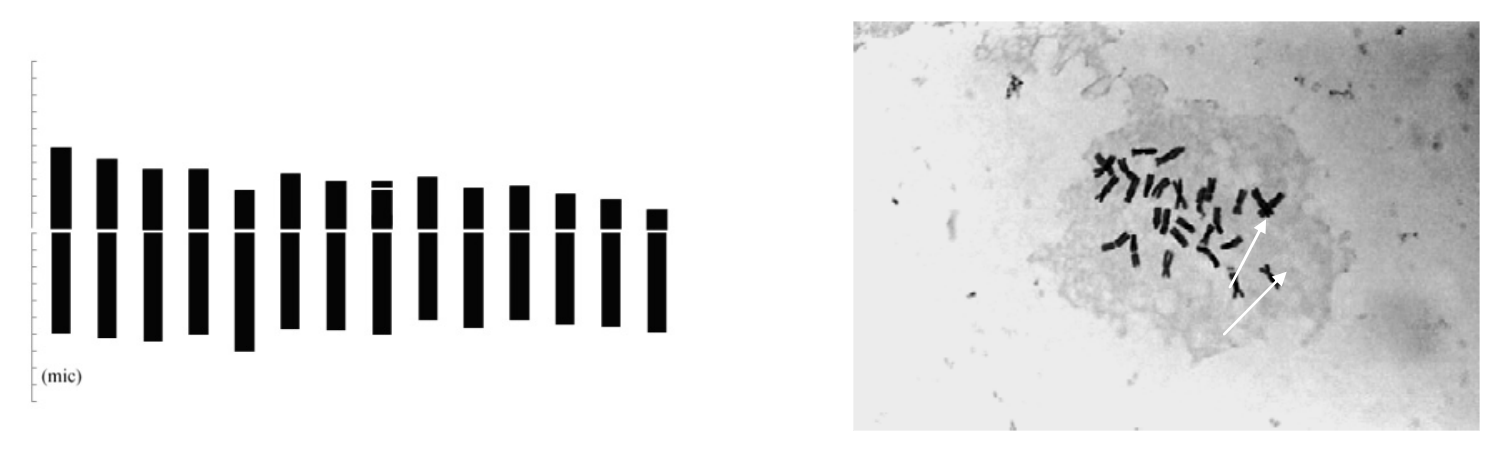

Figure 4 - metaphase chromosomes picture and ideogram of Naghadeh population

*white flash shows satellites
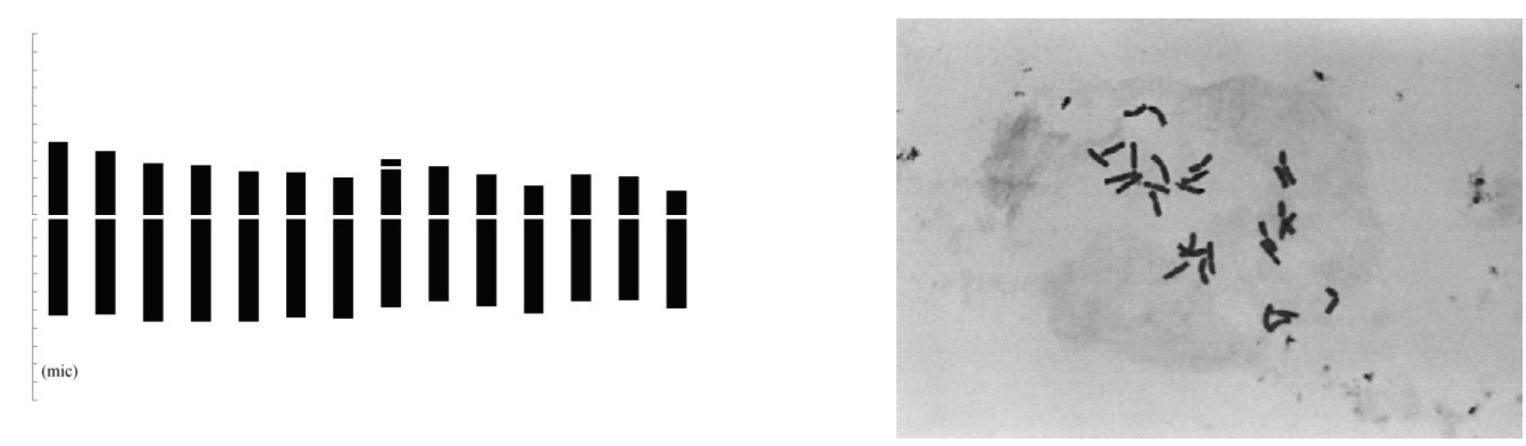

Figure 5 - metaphase chromosomes picture and ideogram of Broujerd population
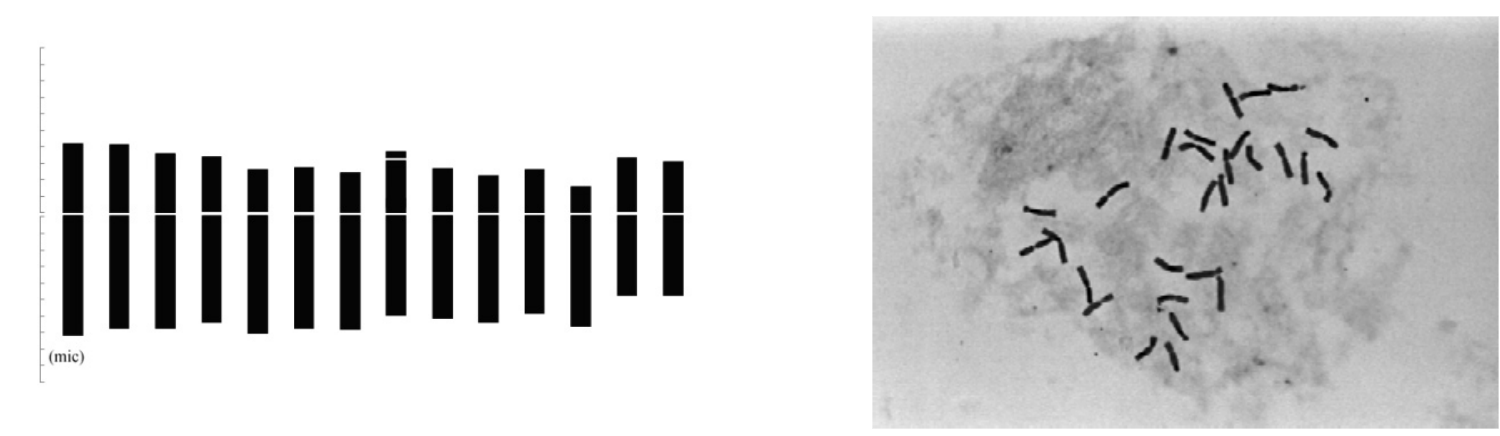

Figure 6 - metaphase chromosomes picture and ideogram of Zanjan population 

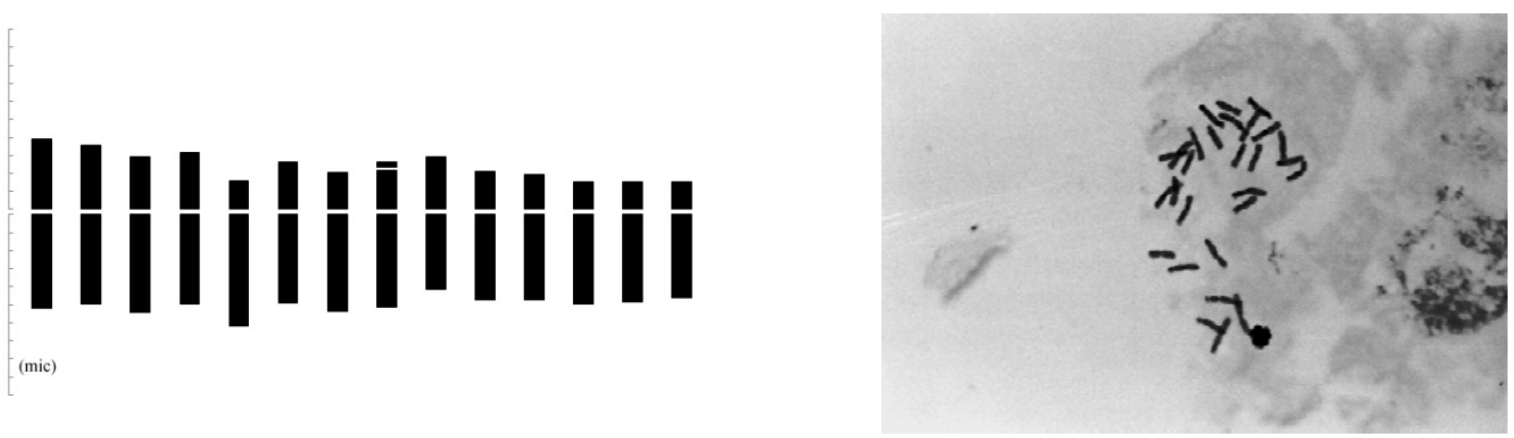

Figure 7 - metaphase chromosomes picture and ideogram of Songhor population
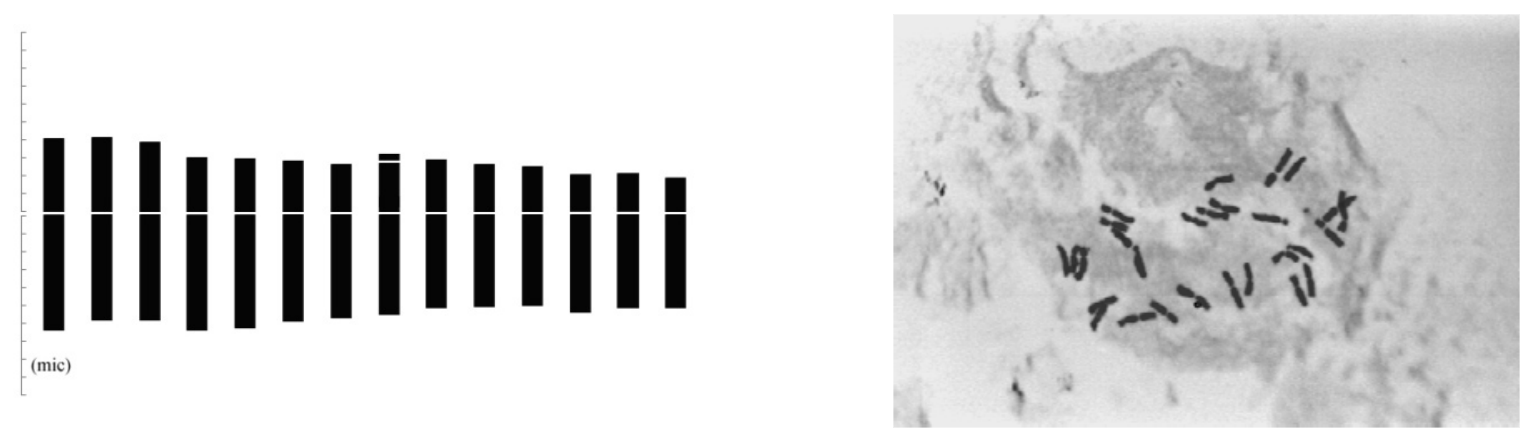

Figure 8 - metaphase chromosomes picture and ideogram of Maragheh population
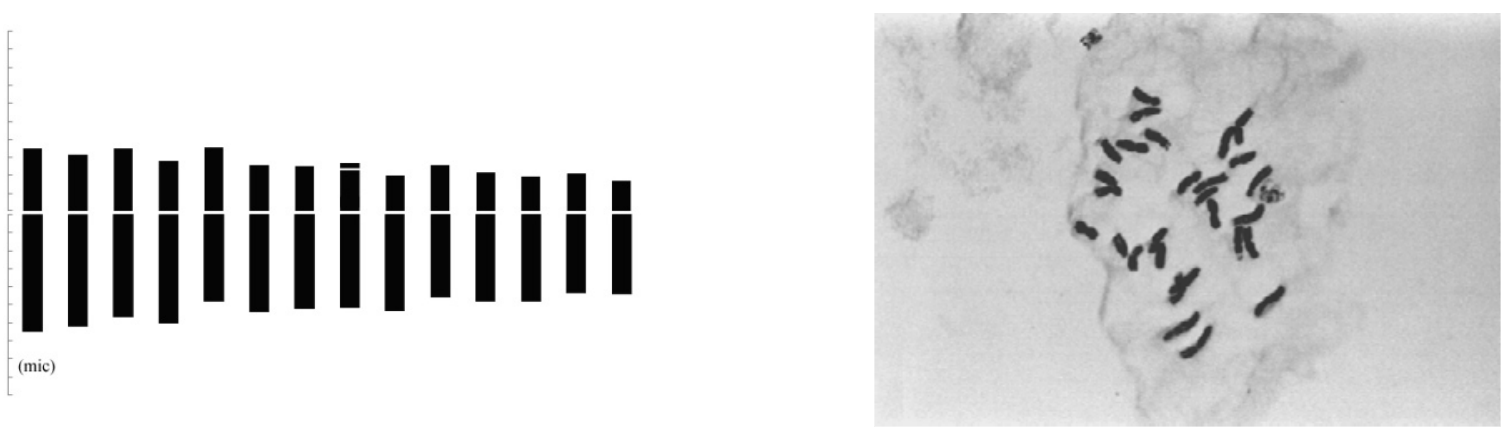

Figure 9 - metaphase chromosomes picture and ideogram of Hashtroud population 

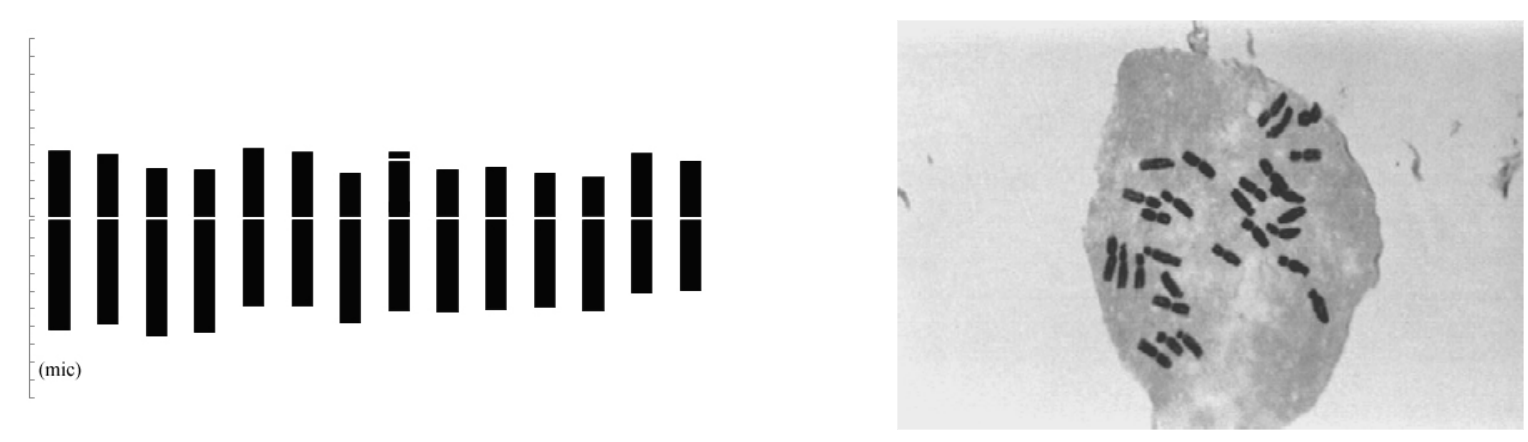

Figure 10 - metaphase chromosomes picture and ideogram of Shirvan population
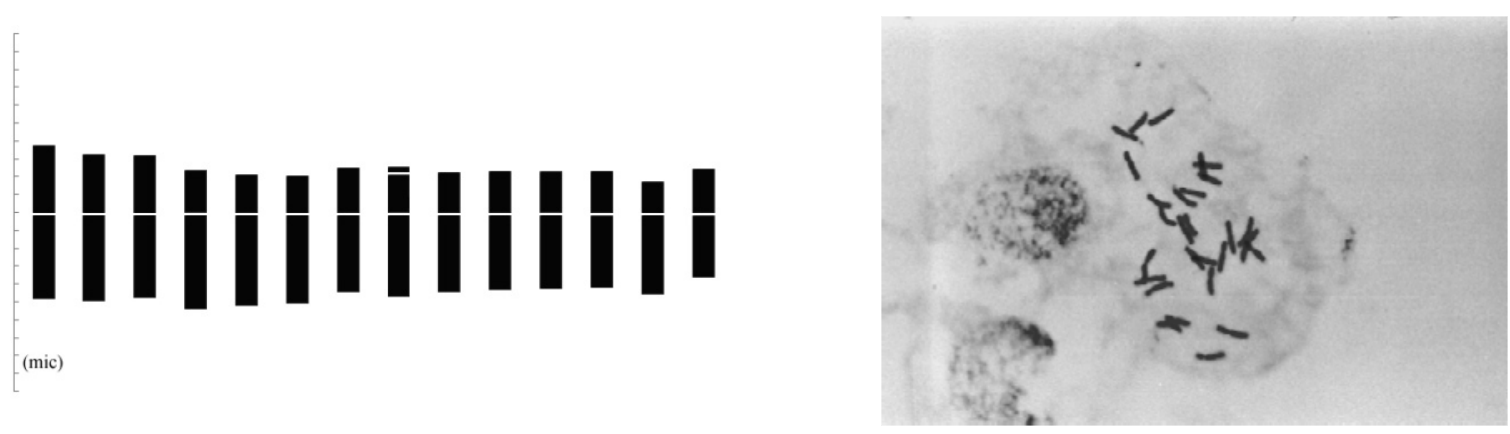

Figure 11 - metaphase chromosomes picture and ideogram of Ardebil population
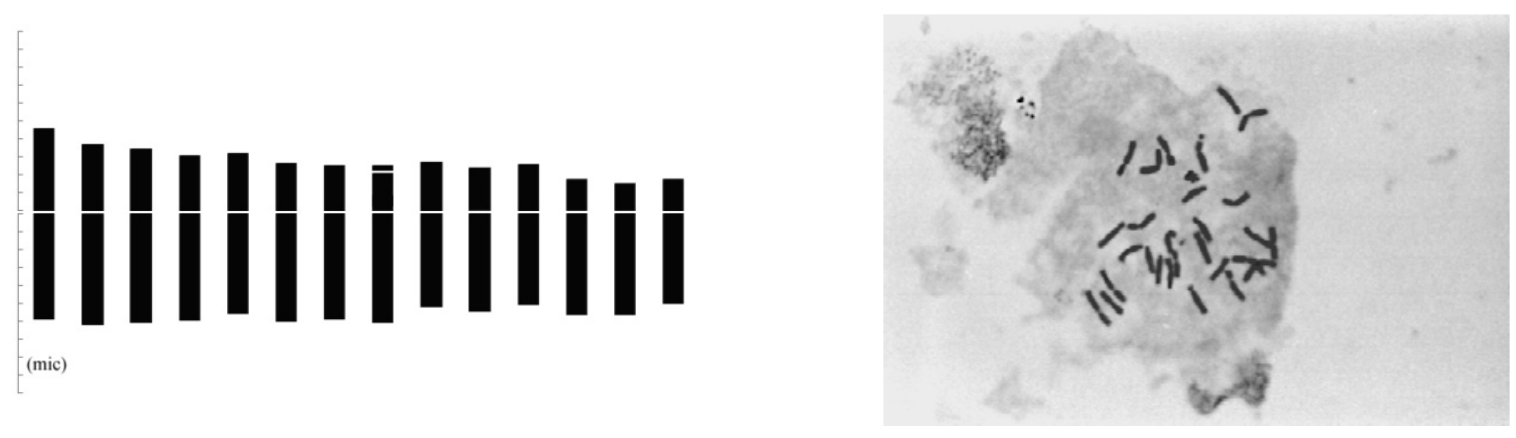

Figure 12 - metaphase chromosomes picture and ideogram of Islam Abad Gharb population 

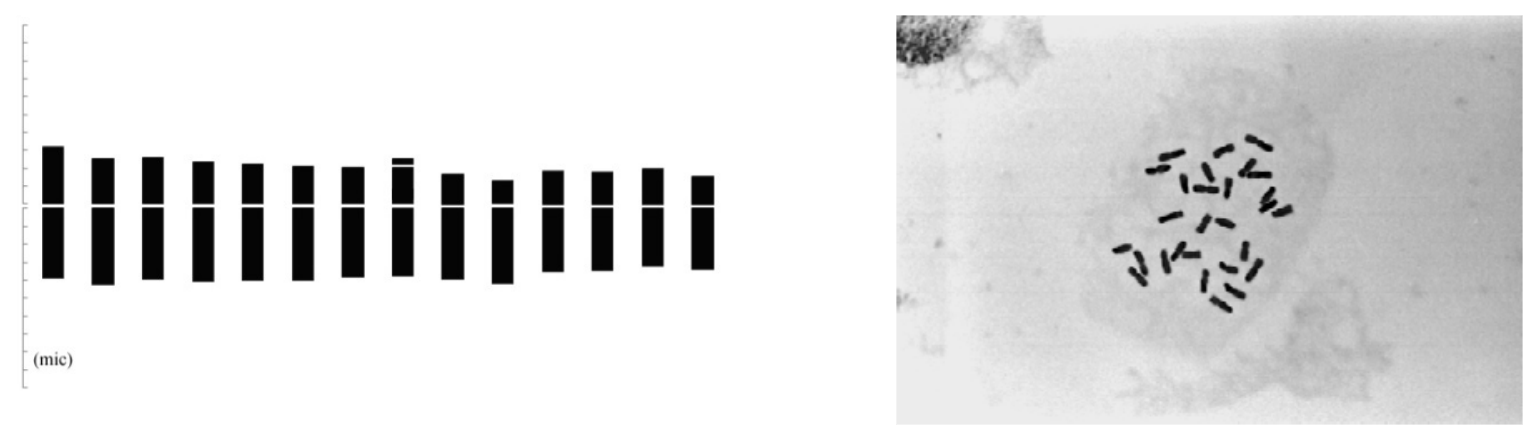

Figure 13 - metaphase chromosomes picture and ideogram of Orumia population
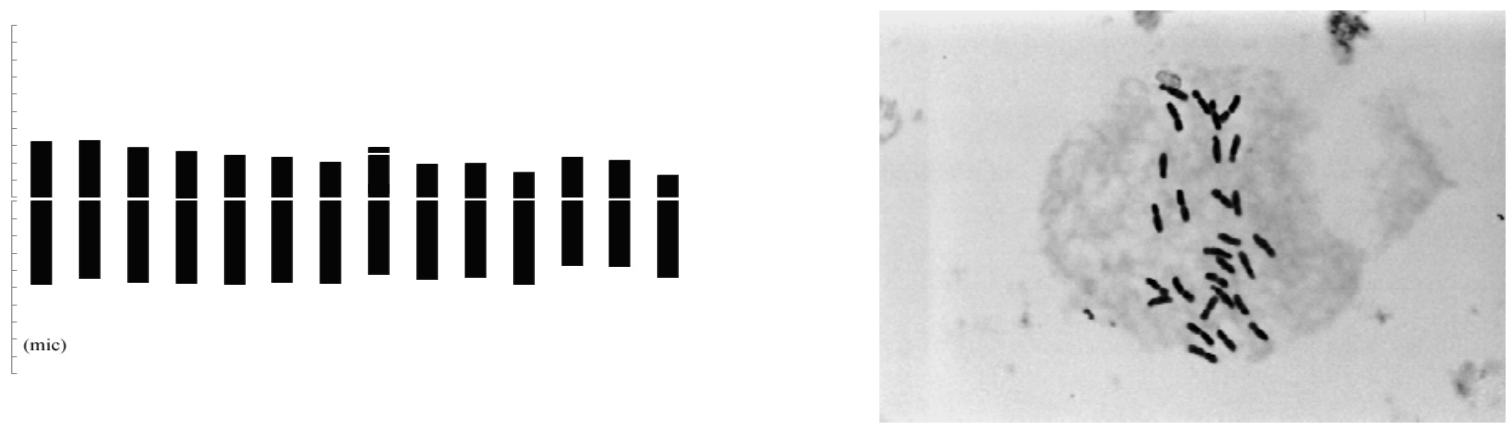

Figure 14 - metaphase chromosomes picture and ideogram of Javanroud population
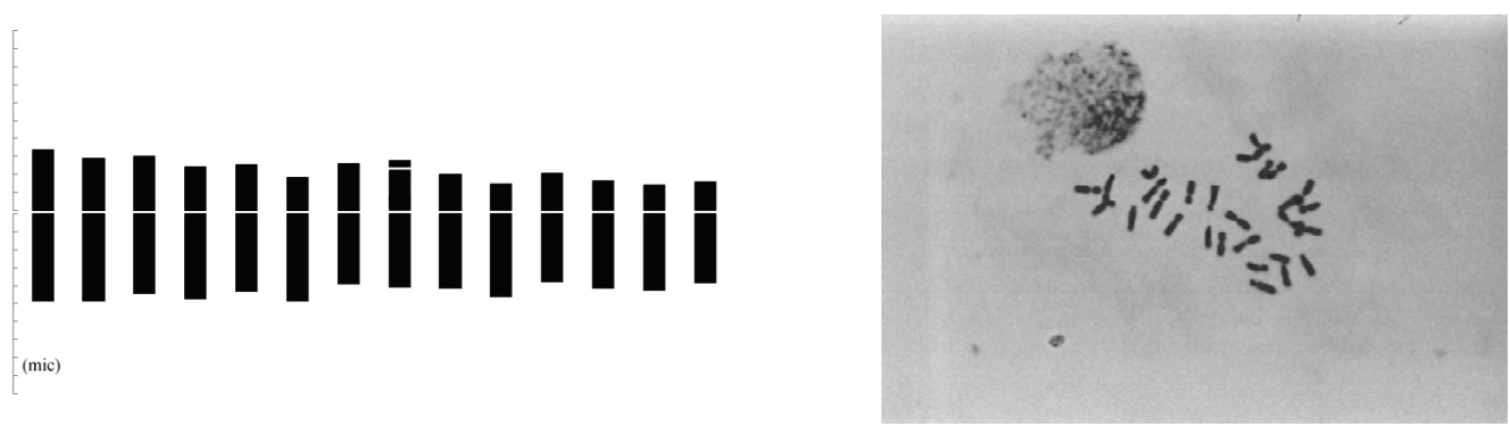

Figure 15 - metaphase chromosomes picture and ideogram of Hamedan population 
1 The results of factor analysis of 9 chromosomal morphology traits showed that the first two

2 factors had Eigen values greater than one with 65.83 to 88.39 percent variance and these two

3 factors were responsible for diversity in the accessions (Tables $7 \& 8$ ).

Table 7. Eigen values, percentage of variance and cumulative variance factor.

\begin{tabular}{llll}
\hline Factors & Eigen values & Percentage of variance & Cumulative variance factor \\
\hline 1 & 5.93 & 65.83 & 65.83 \\
2 & 2.03 & 22.56 & 88.39 \\
\hline
\end{tabular}

Table 8. The first two factors derived from factor analysis for morphological traits of chromosomes.

\begin{tabular}{l|ll}
\hline \multirow{2}{*}{ Traits name } & \multicolumn{2}{l}{ Factors } \\
\cline { 2 - 3 } & $\mathbf{1}$ & $\mathbf{2}$ \\
\hline Range of chromosome length variation & 0.822 & 0.554 \\
Total length of chromosome & 0.970 & 0.138 \\
Average of chromosome length & 0.970 & 0.138 \\
Total length of chromosomes (TLC) & -0.906 & -0.023 \\
Minimum of short arm to long arm ratio percentage & -0.284 & -0.910 \\
Centromere index & -0.713 & -0.187 \\
Standard deviation & 0.806 & .0568 \\
CV of chromosome length & 0.244 & 0.947 \\
Distribution index of chromosome & -0.007 & 0.923 \\
\hline
\end{tabular}

6 Range of chromosome length variation, total length of chromosome, average of chromosome 7 length, total length of chromosomes (TLC), centromere index, and standard deviation of 8 chromosome length traits had the largest factor coefficients in the first factor. Because most of 9 these traits depend on the chromosomes length, this factor is named length of chromosomes. This 10 factor presents 65.83 percent of the total variance that shows there is great diversity for traits 11 related to chromosome length among accessions. In the second factor, CV of chromosome length, 12 minimum of short arm to long arm ratio percentage and distribution index traits had the largest 13 factor coefficients. Thus, the second factor was named as karyotype symmetry duo to all of these 14 traits indicated karyotype symmetry of the accessions. The second factor accounted for 22.55 15 percent of the total variance, indicating that there was no great difference between accessions in 
1 terms of symmetry and confirming the placement of accessions at the 2A position of the Stebbins

2 table. Therefore, the results of factor analysis show that karyotypic variation within accessions is

3 related to the length of chromosomes and there is difference between accessions for their total

4 chromosome length; but the karyotype of different accessions are same for their symmetry and

5 they are relatively symmetrical. As morphological studies were conducted, low coefficient of

6 variation coupled with symmetric karyotype indicates Ae. cylindrica as a recently evolved species.

\section{4. Conclusion}

9 Aegilops cylindrica diversity centers are mostly located in the Northwest regions where the highest 10 numbers of collection sites are distributed. We also observed that Ae. cylindrica accessions of Iran 11 should be treated as a recently evolved species due to low diversity in morphological traits and 12 symmetric karyotypes.

\section{References|}

14 1. van Slageren M.W. 1994. Wild wheats: a monograph of Aegilops L. and Amblyopyrum (Jaub. \& Spach) Eig (Poaceae). Wageningen Agricultural University Papers (94-7):513 pp.

2. Kimber G. \& Feldman M. 1987. Wild wheat. An introduction. Special Report, College of Agriculture, University of Missouri, Columbia (353).

Dewey S. 1996. Jointed goatgrass-an overview of the problem. Proc. of the Pacific Northwest Jointed Goatgrass Conf., Pocatello, ID, pp 1-2.

4. Donald W.W. \& Ogg Jr A.G. 1991. Biology and control of jointed goatgrass (Aegilops cylindrica), a review. Weed Technology:3-17.

Anderson R. 1993. Jointed goatgrass (Aegilops cylindrica) ecology and interference in winter wheat. Weed Science:388-393.

6. Ogg A. 1993. Jointed goatgrass survey-1993. Magnitude and scope of the problem. In Westra and 
$17 . \quad$ Fandrich L. \& Mallory-Smith C.A. 2006. Factors affecting germination of jointed goatgrass (Aegilops $2 \quad$ cylindrica) seed. Weed Science 54(4):677-684.

3 8. Linc G., et al. 1999. Molecular cytogenetic analysis of Aegilops cylindrica Host. Genome 42(3):497-

$59 . \quad$ Tsunewaki K. 1989. Plasmon diversity in Triticum and Aegilops and its implication in wheat 6 evolution. Genome 31(1):143-154.

10. Maan S. 1976. Cytoplasmic Homology between Aegilops squarrosa L. and A. cylindrica Host. Crop Science 16(6):757-761.

11. Gandhi H.T., et al. 2005. Chloroplast and nuclear microsatellite analysis of Aegilops cylindrica. Theoretical and Applied Genetics 111(3):561-572.

12. Badaeva E., et al. 2002. Genome differentiation in Aegilops. 3. Evolution of the D-genome cluster. Plant Systematics and Evolution 231(1-4):163-190.

13. Caldwell K.S., et al. 2004. Sequence polymorphism in polyploid wheat and their D-genome diploid ancestor. Genetics 167(2):941-947.

14. Ogg Jr A.G. \& Seefeldt S.S. 1999. Characterizing traits that enhance the competitiveness of winter wheat (Triticum aestivum) against jointed goatgrass (Aegilops cylindrica). Weed Science:74-80.

15. El Bouhssini M., et al. 1998. Identification in Aegilops species of resistant sources to Hessian fly (Diptera: Cecidomyiidae) in Morocco. Genetic Resources and Crop Evolution 45(4):343-345.

16. Farooq S., Iqbal N., Asghar M., \& Shah T. 1992. Intergeneric hybridization for wheat improvement. 6: Production of salt tolerant germplasm through crossing wheat (Triticum aestivum L.) with Aegilops cylindrica and its significance in practical agriculture. Journal of Genetics and Breeding 46:125-132.

17. Iriki N., Kawakami A., Takata K., Kuwabara T., \& Ban T. 2001. Screening relatives of wheat for snow mold resistance and freeing tolerance. Euphytica 122(2):335-341.

18. Kimber G. \& Zhao Y. 1983. The D genome of the Triticeae. Canadian Journal of Genetics and Cytology 25(6):581-589. 
1 19. Riley R. \& Law C. 1965. Genetic variation in chromosome pairing. Advances in Genetics 13:57-114.

2 20. Gandhi H.T., et al. 2006. Hybridization between wheat and jointed goatgrass (Aegilops cylindrica) 3 under field conditions. Weed Science 54(6):1073-1079.

4 21. Zemetra R., Hansen J., \& Mallory-Smith C. 1998. Potential for gene transfer between wheat $5 \quad$ (Triticum aestivum) and jointed goatgrass (Aegilops cylindrica). Weed Science:313-317.

$622 . \quad$ Dvorak J., Luo M.-C., Yang Z.-L., \& Zhang H.-B. 1998. The structure of the Aegilops tauschii genepool and the evolution of hexaploid wheat. Theoretical and Applied Genetics 97(4):657-670.

8 23. Lubbers E., Gill K., Cox T., \& Gill B. 1991. Variation of molecular markers among geographically diverse accessions of Triticum tauschii. Genome 34(3):354-361.

10 24. Pestsova E., Börner A., \& Röder M. 2001. Development of a Set of Triticum Aestivum-Aegilops Tauschii Introgression Lines. Hereditas 135(2-3):139-143.

25. Bakhshi B., Aghaei M., Bihamta M., Darvish F., \& Zarifi E. 2010. Ploidy determination of Aegilops cylindrica Host accessions of Iran by using flow cytometry and chromosome counting. Iran J Bot $16(2): 258-266$.

26. Levan A., Fredga K., \& Sandberg A.A. 1964. Nomenclature for centromeric position on chromosomes. Hereditas 52(2):201-220.

Hennink S. \& Zeven A. 1990. The interpretation of Nei and Shannon-Weaver within population variation indices. Euphytica 51(3):235-240.

28. Mujeeb-Kazi A. \& Miranda J. 1985. Enhanced resolution of somatic chromosome constrictions as an aid to identifying intergeneric hybrids among some Triticeae. Cytologia 50(4):701-709.

21 29. Forni-Martins E. 1994. Karyotypes of species of Sesbania Scop. Cytologia 59:13-18.

22 30. Bennardello L. 1994. Karyotypic studies in Solanum section Lasiocarpa. American Journal of Botany 81:95-103.

24 31. Sheidai M., Vojdani P., \& Alishah O. 1996. Karyological Studies in Gossypium herbaceum Cultivars of Iran. Cytologia 61(4):365-374. 
1 32. Datta M. \& Agarwal B. 1992. Intervarietal Differences in Karyotype of Tea. Cytologia 57(4):437-441.

2 33. Lavania U. \& Srivastava S. 1999. Quantitative delineation of karyotype variation in Papaver as a 3 measure of phylogenetic differentiation and origin. Current Science (Bangalore) 77:429-435.

4 34. Reeves A. 2001. MicroMeasure: a new computer program for the collection and analysis of $5 \quad$ cytogenetic data. Genome 44(3):439-443.

6 35. Jaaska V. 1981. Aspartate aminotransferase and alcohol dehydrogenase isoenzymes: Intraspecific 7 differentiation inAegilops tauschii and the origin of the D genome polyploids in the wheat group. Plant Systematics and Evolution 137(4):259-273.

9 36. Nakai Y. 1978. The origin of the tetraploid wheats revealed from the study on esterase isozymes. Proc. 5th Int. Wheat Genet. Symp., New Delhi, pp 108-119.

11 37. Asghar M., Rao A., \& Farooq S. 2001. Evidence of homoeologous relationship between chromosomes of wheat and Aegilops geniculata. Pakistan Journal of Biological Science 4:411-413.

13 38. Aghaei M.J., Mozafari J., Taleei A.R., Naghavi M.R., \& Omidi M. 2008. Distribution and diversity of Aegilops tauschii in Iran. Genetic Resources and Crop Evolution 55(3):341-349.

39. Ranjbar M., Naghavi M., Zali A., \& Aghaei M. 2007. Multivariate analysis of morphological variation in accessions of Aegilops crassa from Iran. Pakistan Journal of Biological Science 10(7):1126-1129.

40. Peet R.K. 1974. The measurement of species diversity. Annual Review of Ecology and Systematics:285-307. 